\title{
Analysis of risk factors for multidrug-resistant organisms in diabetic foot infection
}

\author{
Xi Yan ${ }^{1 \dagger}$, Jin-fang Song ${ }^{2,3^{*}+}$, Liang Zhang ${ }^{4}$ and Xia Li ${ }^{2}$
}

\begin{abstract}
Background: To study the bacteriological characteristics, risk factors, and treatment of multi-drug resistance (MDR) organisms in patients with diabetic foot infection.

Methods: Patients with diabetic foot ulcer admitted to hospital from June 2018 to December $2019(n=180)$ were selected as clinical subjects. Demographic information, routine blood test, wound culture and sensitivity were collected. Risk factors of MDR bacteria were analyzed.
\end{abstract}

Results: Among 180 patients with diabetic foot ulcer, 146 were positive in bacterial culture, with 84 positive in MDR bacteria. A total of 182 strains were isolated, with 104 strains being multi-drug resistant. Body mass index, glycosylated hemoglobin, fasting blood glucose, triglyceride, course of ulcer, size of ulcer, peripheral neuropathy, peripheral vascular disease, osteomyelitis, peripheral blood leukocyte count, percentage of neutrophils, and previous use of antibiotics were the related factors of infection of MDR bacteria in diabetic foot ulcer patients $(P<0.05)$. The leukocyte count and neutrophil ratio of MDR-bacilli were lower than those of non MDR-bacilli $(P<0.05)$.

Conclusion: The risk of MDR bacteria in diabetic foot infection is high. It is necessary to evaluate the risk of multidrug-resistant bacteria by characterizing the course of disease, metabolic control, local ulcer and other aspects in order to formulate an effective treatment plan. The decrease of leukocyte count and neutrophil ratio may be related to damage of the host immune response.

Keywords: Diabetic foot ulcers, Diabetic food infection, Multidrug-resistant bacteria

\section{Background}

Diabetic patients often have a high prevalence of diabetic foot infection (DFI) due to associated neuropathy, peripheral vascular disease, immune abnormalities, etc. Some studies have shown that about $15 \%$ of diabetic patients can develop foot ulcers during their lifetime [1]. Diabetic foot ulcer wounds contain a large number of protein and carbohydrate nutrients, which can be a nidus for infection. About $40 \%$ to $80 \%$ of patients with diabetic foot suffer from a concurrent infection. $25 \%$ of patients

*Correspondence: songjinfang1987@126.com

${ }^{+} X i$ Yan and Jin-fang Song contributed equally to this work.

${ }^{2}$ Department of Clinical Pharmacy, Affiliated Hospital of Jiangnan

University, Wuxi City, Jiangsu Province, China

Full list of author information is available at the end of the article with mild infection develops with severe deep infection. Clinically, the disease develops rapidly for a certain proportion of patients with mild infection and they need attention [2]. The types of diabetic foot infections are complex and varied. In addition to the common cellulitis, complications can involve osteomyelitis and gangrene [3]. Since the increasingly severe form of prevention and treatment of diabetic foot ulcer infections is associated with a high rate of detection of multi-drug resistant bacteria, it is important to focus on assessing the risk factors of multi-drug resistant bacterial infections in order to find more effective treatment [4-6]. Multi-drug resistance (MDR) organisms refer to bacteria that exhibit drug resistance to three or more commonly used antibiotics that are usually sensitive. Multiple drug resistance also includes extensive drug resistance (XDR) and pan-drug 
resistance (PDR). Clinically, Common MDR include methicillin-resistant staphylococcus aureus (MRSA), vancomycin-resistant enterococcus (VRE), bacteria that produce ultra-broad spectrum $\beta$-lactamase (ESBLs) in enterobacteriaceae (such as escherichia coli and klebsiella pneumoniae), carbapenem-resistant enterobacteriaceae, multidrug-resistant Pseudomonas aeruginosa (MDR-PA), multi-drug resistant acinetobacter baumannii (MDR-AB), etc. [7]. The aim of this study is to analyze the bacteriological characteristics of diabetic foot ulcers, drug resistance of isolates, and to reveal the potential risk factors for multi-drug resistant bacteria. This allows for more effective assessment and treatment plans for patients with MDR diabetic foot infections.

\section{Methods \\ Study design}

A total of 180 patients (96 males and 84 females) with diabetic foot ulcer admitted to our hospital from June 2018 to December 2019 were analyzed retrospectively. Their demographic information, medication history, laboratory investigations, and adverse drug reactions were collected. Inclusion criteria: (1) The diagnosis of diabetic foot was met based on relevant diagnosis and treatment guidelines $[8,9]$, and the diagnostic criteria of diabetic foot infection in the Normalized and Standardized Diagnosis and Treatment of Diabetic Foot Infection [10] were met. (2) Ulcers grading 1 to 4 based on the Wagners grading system [11]. Exclusion criteria: (1) Acute complications of diabetes mellitus other than diabetic foot ulcers. (2) Complications involving other serious cardiovascular and cerebrovascular diseases, liver and kidney insufficiency, etc. (3) Other non-diabetic foot ulcers due to vascular insufficiency, cardiac diseases, neurological disorders, malignancies, etc. This study was carried out in accordance with the recommendations of the Ethics Committee of the Affiliated Hospital of Jiangnan University (Original Area of Wuxi Third People's Hospital) with written informed consent from all subjects.

\section{Collection of clinical index}

Detailed history taking and physical examination was performed for each patient, and information on age,sex, height, weight, duration of diabetes, course of ulcer, site and size of ulcer, number of ulcers, use of antibiotics, and comorbidities were recorded. The size of the ulcer will be calculated by multiplying the length and width. The body mass index (BMI) was calculated by weight $(\mathrm{kg}) /$ height $^{\wedge} 2$ $\left(\mathrm{m}^{\wedge} 2\right)$. Routine blood work including fasting plasma glucose (FPG), glycated hemoglobin (HbA1c), blood pressure, total cholesterol (TC), triglyceride (TG), lowdensity lipoprotein (LDL-c), and high-density lipoprotein
(HDL-c) were collected. X-ray, CT, or MRI examination were used to diagnose osteomyelitis.

\section{Microbiological detection}

Specimen collection will be performed before the use of antibiotics, deep necrotic tissue or secretions from diabetic foot ulcers should be collected, and the specimens will be placed in sterilized tubes for examination within $1 \mathrm{~h}$. Isolation, culture and drug sensitivity analysis of pathogenic bacteria should be performed according to standard operation procedures. VITEK-2 automatic bacterial identification system of bioMerieux (France) and its matching kit drug sensitivity card will be used for bacterial culture and drug sensitivity test.

According to China Clinical Laboratory Procedures (the Fourth Edition), isolated culture and identification of pathogenic bacteria are carried out. VITEK-2 Compact (BioMerieux bv, France) is used for bacterial identification and drug sensitive test. The minimal inhibitory concentration (MIC) dilution method is used for drug sensitive test, and the criterion of results refers to the 2016 edition relevant standards of American Institute for Clinical and Laboratory Standardization (CLSI M100-S26). Results are reported by sensitivity (S), intermediary (I), and resistance (R) [12].

\section{Statistical analysis}

SPSS 18.0 software was used for statistical analysis. Measurement data will be expressed as mean \pm standard deviation, and enumeration data will be expressed as percentage; $t$-test or $\chi^{2}$ test will be used for comparison of different groups, and logistic regression model will be used for multivariate analysis; $P<0.05$ shall be considered statistically significant.

\section{Results}

Bacteriological condition of diabetic foot ulcer infection

A total of 180 patients with diabetic foot ulcers were included in this study, $146(81.11 \%)$ were positive for wound culture, of which $62(42.47 \%)$ had antibiotic-sensitive organisms and 84 (57.53\%) had multidrug-resistant organisms. A total of 182 strains of bacteria were cultured, among which, 78 strains were antibiotic-sensitive (41 strains of gram-negative bacteria and 37 strains of gram-positive bacteria), 104 strains were multidrugresistant bacteria (66 strains of gram-negative bacteria and 38 strains of gram-positive bacteria). See Table 1 for details.

\section{Correlation between multidrug-resistant bacteria infection and clinical indexes in patients with diabetic foot ulcer}

In patients with diabetic foot ulcer infection, the correlation between infection with multi-drug resistant 
Table 1 Bacterial Culture and Distribution of Multidrug-resistant Bacteria in Patients with Diabetic Foot ulcer infection

\begin{tabular}{llll}
\hline Bacteria & Number of sensitive strains (\%) & $\begin{array}{l}\text { Number of multidrug-resistant } \\
\text { strains (\%) }\end{array}$ & Total (\%) \\
\hline Gram-negative bacteria & $\mathbf{4 1 ( 3 8 . 3 2 )}$ & $\mathbf{6 6 ( 6 1 . 6 8 )}$ & $\mathbf{1 0 7 ( 5 8 . 7 9 )}$ \\
$\quad$ Escherichia coli & $16(36.36)$ & $28(63.64)$ & $44(24.18)$ \\
Pseudomonas aeruginosa & $15(36.59)$ & $26(63.41)$ & $\mathbf{4 1}(22.53)$ \\
Acinetobacter & $3(30.00)$ & $7(70.00)$ & $10(5.49)$ \\
Transmorphobacteria & $3(37.50)$ & $5(62.50)$ & $8(4.40)$ \\
Enterobacterium & $2(100)$ & $0(0)$ & $2(1.10)$ \\
Morganifella & $2(100)$ & $0(0)$ & $2(1.10)$ \\
Gram-positive bacteria & $\mathbf{3 7 ( 4 9 . 3 3 )}$ & $\mathbf{3 8 ( 5 0 . 6 7 )}$ & $\mathbf{7 5 ( 4 1 . 2 1 )}$ \\
Staphylococcus aureus & $19(37.25)$ & $32(62.75)$ & $51(28.02)$ \\
Coagulase negative staphylococcus & $5(100)$ & $0(0)$ & $5(2.75)$ \\
Enterococcus & $11(64.71)$ & $6(35.29)$ & $17(9.34)$ \\
$\beta$ hemolytic streptococcus in group B & $2(100)$ & $0(0)$ & $2(1.10)$ \\
\hline
\end{tabular}

bacteria and various clinical indexes of patients is shown in Table 2. BMI, HbA1c, FPG, TG, ulcer course, ulcer size, peripheral neuropathy, peripheral vascular disease, peripheral blood leucocyte count, neutrophil percentage, and use of antimicrobial agents in the past 3 months were significantly different between the group of patients infected with sensitive bacteria and the group of patients infected with multiple drug-resistant bacteria $(P<0.05)$; other parameters such as sex, age, duration of diabetes, TC, HDL-c, LDL-c, Wagners' grade, hypertension, retinopathy, and nephropathy were not significantly different between the two groups of patients $(P>0.05)$.

\section{Analysis of multiple drug-resistant bacteria infection in patients with diabetic foot ulcer}

BMI, HbA1c, FPG, TG, ulcer course, ulcer size, peripheral neuropathy, peripheral vascular lesions, osteomyelitis, peripheral blood leucocyte count, neutrophil percentage, and use of antimicrobial drugs within the last 3 months were factors associated with the presence of multi-drug resistant bacterial infections in patients with diabetic foot ulcers $(P<0.05)$, as shown in Table 3.

\section{Discussion}

This is a preliminary study of patients with diabetic foot ulcer in which each hospitalized subject was evaluated for bacteriology, clinical indexes, and antimicrobial drug use. Proper wound cleaning and debridement and collection of pus or soft tissue specimens for bacteriological culture were performed in all cases [13], and the bacteriological characteristics of diabetic foot ulcer infections and risk factors for multi-drug resistant bacterial infections were analyzed based on the culture results.

Earlier studies reported that Gram-positive bacteria such as Staphylococcus aureus and Enterococcus faecalis were considered as the most common flora of diabetic foot infections, followed by Gram-negative bacteria such as Escherichia coli and Pseudomonas aeruginosa [14, 15]. In recent years, the bacterial spectrum of diabetic foot infections has shifted considerably with the evolution of diabetes epidemiology and changes in the application of antimicrobial drugs $[16,17]$. In our study, 182 strains of bacteria were cultured, including 107 strains of gram-negative aerobic bacteria, and the ratio of gramnegative bacteria to gram-positive bacteria was 1.47 , which indicated that empirical antibacterial drug therapy for diabetic foot ulcer infection should pay attention to assessing the risk of gram-negative bacteria infection. Staphylococcus aureus was the most common bacterium among all aerobic bacteria, and 51 strains $(28.02 \%)$ were cultured, which was consistent with the bacteriological characteristics of skin and soft tissue infections [18]. In the analysis of bacterial resistance, it was found that Staphylococcus aureus was the main multi-drug resistant bacteria in diabetic foot ulcer infection, and the resistance rate of Escherichia coli was the highest among gramnegative bacteria, followed by Pseudomonas aeruginosa, which was consistent with previous reports [19]. Infection with multidrug-resistant bacteria in diabetic foot ulcers increases the difficulty of treatment by reducing the clinical effect of antibiotics therapy, leading to amputations or deaths $[5,11]$. Due to the increased resistance rate of Escherichia coli and Pseudomonas aeruginosa among gram-negative bacteria, the risk factors of drugresistant negative bacilli in patients should be evaluated in the development of initial anti-infective treatment regimen in clinical practice. In this study, multidrug-resistant bacteria accounted for up to $57.14 \%$ of the strains obtained by wound cultures, which may be related to the patients with serious illness admitted to our hospital as 
Table 2 Comparison of clinical indexes of diabetic foot ulcer patients infected with sensitive bacteria and multidrug resistant bacteria

\begin{tabular}{|c|c|c|c|}
\hline Index & $\begin{array}{l}\text { Infected with Sensitive } \\
\text { Bacteria }(n=62)\end{array}$ & $\begin{array}{l}\text { Infected with Multidrug resistant } \\
\text { bacteria }(n=84)\end{array}$ & $P$ Value \\
\hline $\operatorname{Sex}(M / F)$ & $41 / 21$ & $52 / 32$ & 0.600 \\
\hline Age & $50.24 \pm 8.71$ & $49.39 \pm 12.29$ & 0.643 \\
\hline Diabetes duration (years) & $10.51 \pm 6.32$ & $9.75 \pm 5.94$ & 0.458 \\
\hline $\mathrm{BMI}\left(\mathrm{kg} / \mathrm{m}^{2}\right)$ & $24.87 \pm 3.18$ & $30.11 \pm 3.61$ & $0.000^{*}$ \\
\hline $\mathrm{HbA1c( \% )}$ & $7.91 \pm 0.85$ & $9.82 \pm 0.93$ & $0.000^{*}$ \\
\hline $\mathrm{FPG}(\mathrm{mmol} / \mathrm{l})$ & $9.35 \pm 1.74$ & $11.51 \pm 1.90$ & $0.000^{*}$ \\
\hline $\mathrm{TG}(\mathrm{mmol} / \mathrm{l})$ & $2.05 \pm 1.58$ & $2.69 \pm 0.92$ & $0.003^{*}$ \\
\hline $\mathrm{TC}(\mathrm{mmol} / \mathrm{l})$ & $4.67 \pm 1.20$ & $4.45 \pm 0.88$ & 0.203 \\
\hline $\mathrm{HDL}-\mathrm{c}(\mathrm{mmol} / \mathrm{l})$ & $1.29 \pm 0.45$ & $1.31 \pm 0.38$ & 0.772 \\
\hline LDL-c $(\mathrm{mmol} / \mathrm{l})$ & $2.79 \pm 0.80$ & $2.87 \pm 0.78$ & 0.546 \\
\hline Ulcer course(Month) & $1.51 \pm 0.92$ & $2.20 \pm 1.26$ & $0.000^{*}$ \\
\hline Ulcer size $\left(\mathrm{cm}^{2}\right)$ & $15.21 \pm 10.41$ & $26.12 \pm 14.79$ & $0.000^{*}$ \\
\hline \multicolumn{4}{|l|}{ Wagners Grade } \\
\hline I & $2(3.23 \%)$ & $4(4.76 \%)$ & 0.644 \\
\hline$\|$ & $25(40.32)$ & $31(36.90 \%)$ & 0.675 \\
\hline$\|$ & $12(19.35 \%)$ & $16(19.05 \%)$ & 0.963 \\
\hline IV & $23(37.10 \%)$ & 33(39.29\%) & 0.788 \\
\hline \multicolumn{4}{|l|}{ Amorbidities } \\
\hline Hypertension & $24(38.71 \%)$ & $38(45.24 \%)$ & 0.430 \\
\hline Retinopathy & $32(51.61 \%)$ & $47(55.95 \%)$ & 0.603 \\
\hline Peripheral neuropathy & $25(40.32 \%)$ & $57(67.86 \%)$ & $0.001^{*}$ \\
\hline Kidney disease & $32(51.61 \%)$ & $47(55.95 \%)$ & 0.603 \\
\hline Peripheral vascular lesions & $28(45.16 \%)$ & $61(72.62 \%)$ & $0.001^{*}$ \\
\hline Osteomyelitis & $5(8.06 \%)$ & $24(28.57 \%)$ & $0.002^{*}$ \\
\hline White blood cell count $\left({ }^{*} 10^{3}\right)$ & $9.21 \pm 1.87$ & $6.51 \pm 1.77$ & $0.000^{*}$ \\
\hline Neutrophil percentage (\%) & $50.13 \pm 17.61$ & $38.42 \pm 15.25$ & $0.000^{*}$ \\
\hline $\begin{array}{l}\text { Use of antimicrobial drugs within the last } \\
3 \text { months }\end{array}$ & $36(58.06 \%)$ & $64(78.05 \%)$ & $0.020^{*}$ \\
\hline
\end{tabular}

Abbreviations: BMI Body mass index, HbA1c Hemoglobin A1c, FPG Fasting plasma glucose, TG Triglyceride, TC Total cholesterol, HDL-C High-density lipoproteincholesterol, LDL-C Low-density lipoprotein-cholesterol

Data are expressed as mean \pm SD or percentage. ${ }^{*} P<0.05$ compared with infected with sensitive bacteria group

a tertiary care hospital and the more complex history of antibacterial drug use.

The results of multivariate analysis indicated that BMI, HbA1c, FPG, TG, ulcer course, ulcer size, peripheral neuropathy, peripheral vascular disease, osteomyelitis, peripheral blood leucocyte count, neutrophil percentage, and use of antimicrobial agents in the past 3 months were factors associated with multidrug-resistant bacteria in diabetic foot ulcer infections. Patients infected with multidrug-resistant bacteria have higher BMI, HbA1c, FPG, and TG levels, indicating that substandard metabolic management including body weight, blood glucose, and blood lipids increases the risk of multidrug-resistant bacteria infection. Dubský and other reports show that HbA1c greater than $7.5 \%$ is an important risk factor for ulcer recurrence. The results of this study also confirmed that long-term poor blood glucose control is a factor in the emergence of multidrug-resistant bacteria [20]. The proportion of diabetic foot in patients with $\mathrm{BMI}<25 \mathrm{~kg} /$ $\mathrm{m} 2$ was significantly increased, and low BMI was a risk factor for diabetic foot symptoms. Low BMI would lead to malnutrition of diabetic patients, and the ability to control blood sugar, blood lipid and blood pressure of elderly diabetic patients with deficient nutrition will be reduced, which will often lead to the development of diabetic foot and related complications. Diabetic patients have poor metabolic control ability. Long-term hyperglycemia leads to long-term excessive consumption of patients' bodies, atherosclerosis of blood vessels and long-term disorder of blood lipids. High TG level can affect the blood supply function of feet and aggravate infection ulcer [21].

The course of ulcer and the size of ulcer are important indicators for evaluating the wound condition of 
Table 3 Multi-factor Logistic Regression Analysis of Multiple Drug-resistant Bacteria Infected with Diabetic Foot Ulcer

\begin{tabular}{|c|c|c|c|c|c|c|}
\hline Related Factors & $\beta$ & SE & Wald & OR Value & $95 \% \mathrm{Cl}$ & $P$ Value \\
\hline $\mathrm{BMI}\left(\mathrm{kg} / \mathrm{m}^{2}\right)$ & 1.572 & 0.883 & 6.342 & 1.309 & $1.214 \sim 2.419$ & $0.021^{*}$ \\
\hline $\mathrm{HbA1c}(\%)$ & 0.734 & 0.619 & 4.529 & 2.013 & $2.104 \sim 3.872$ & $0.008^{*}$ \\
\hline $\mathrm{FPG}(\mathrm{mmol} / \mathrm{l})$ & 1.493 & 0.743 & 7.094 & 1.843 & $1.378 \sim 2.351$ & $0.001^{*}$ \\
\hline $\mathrm{TG}(\mathrm{mmol} / \mathrm{l})$ & 1.602 & 0.752 & 9.075 & 1.696 & $1.370 \sim 2.542$ & $0.006^{*}$ \\
\hline Ulcer course(Month) & 0.641 & 0.162 & 16.317 & 1.901 & $1.253 \sim 3.412$ & $0.001^{*}$ \\
\hline Ulcer size $\left(\mathrm{cm}^{2}\right)$ & 0.908 & 0.831 & 10.382 & 2.018 & $1.019 \sim 3.998$ & $0.044^{*}$ \\
\hline Perieral neuropathy & 1.021 & 0.422 & 9.367 & 1.678 & $1.111 \sim 2.535$ & $0.014^{*}$ \\
\hline Peripheral vascular lesions & 1.109 & 0.538 & 12.324 & 1.635 & $1.055 \sim 2.533$ & $0.028^{*}$ \\
\hline Osteomyelitis & 1.532 & 0.647 & 8.305 & 1.696 & $1.140 \sim 2.524$ & $0.009^{*}$ \\
\hline White blood cell count $\left({ }^{*} 10^{3}\right)$ & 0.694 & 0.271 & 11.432 & 1.662 & $1.089 \sim 2.535$ & $0.018^{*}$ \\
\hline Neutrophil percentage (\%) & 1.561 & 0.664 & 5.521 & 2.261 & $1.091 \sim 4.685$ & $0.028^{*}$ \\
\hline $\begin{array}{l}\text { Use of antimicrobial drugs within the } \\
\text { last } 3 \text { months }\end{array}$ & 0.625 & 0.172 & 14.317 & 1.962 & $1.321 \sim 3.875$ & $0.011^{*}$ \\
\hline
\end{tabular}

Abbreviations: BMI Body mass index, HbA1c Hemoglobin A1c, FPG Fasting plasma glucose, TG Triglyceride. ${ }^{*} P<0.05, P$ values are determined by logistic regression model

patients. The findings show that the patients with delayed ulcer healing and large ulcer wound have a greater risk of multi-drug resistant bacterial infection. The longer the wound time of diabetic foot ulcer is, the higher the Wagner grade is, and the proportion of severe infection and mixed infection of the wound increases, which may be related to the decrease of immune function during the infection of diabetic foot ulcer, which leads to the increase of drug-resistant bacteria infection. The bacterial reproduction of the wound deepens the degree of tissue damage and then prolongs the course of disease. These processes are in vicious circles [22].Patients with peripheral neuropathy and peripheral vascular disease often have sensory loss and wound disorder, which are the deep-seated causes of prolonged ulcer healing and recurrent infection. Irrational use of antibacterial drugs is closely related to bacterial resistance. This study found that the risk of multi-drug resistant bacterial infection in patients who used antibacterial drugs in the past 3 months may be greater. Multiple use of antibacterial drugs during treatment can also form a pressure screen to have an effect on bacterial resistance. Subjects with osteomyelitis often use antibacterial drugs with more types, higher intensity and longer course of treatment, which will also increase the risk of pathogen resistance to a certain extent.

The leukocyte count and neutrophil percentage were within the normal range in both groups of patients with diabetic foot ulcers infected with sensitive and multidrug resistant bacteria, but the leukocyte count and neutrophil ratio were lower in patients infected with multi-drug resistant bacteria compared to those infected with sensitive bacteria. Both leukocytes and neutrophils have important roles in physiological and pathological processes, such as angiogenesis, hematopoiesis, wound healing, inflammation, and infectious diseases [19, 23]. The important role of neutrophils in the production and function of pro- and anti-inflammatory-related cytokines has been investigated using humans and animals as subjects, and impaired host immune responses as manifested by decreased inflammatory cell numbers and functions can affect the trauma repair process [24]. Impaired host immune response may be one of the factors associated with multi-drug resistant bacteria infection in patients with diabetic foot ulcers. Currently, no literature has been reported on the effect of multi-drug resistant bacterial infections on the immune response capacity. The treatment of diabetic foot ulcer coinfection includes systemic therapy and topical therapy, namely systemic antibiotic therapy and topical debridement. In diabetic foot ulcer coinfection, thorough debridement is the basis for successful treatment of diabetic foot ulcer. When patients have poor systemic resistance, usually combining with bacteremia or sepsis, systemic antibacterial therapy will be necessary for them. Therefore, it is necessary to conduct a comprehensive assessment of individual patients with diabetic foot ulcers, monitor the degree of infection and changes in pathogenic bacteria, and carry out antiinfective therapy in a standardized manner. At present, it is suggested that the treatment time of antibiotics for patients with mild foot infection should be 1 to 2 weeks, that for moderate and severe infection should be 2 to 3 weeks, and that for some can be extended to 4 weeks. It is not recommended to simply consider missing clinical symptoms as a sign of drug withdrawal because patients with diabetic foot ulcer lack of specificity of clinical 
symptoms. It should be comprehensively considered in combination with other clinical indicators [2].

In conclusion, this study found that patients diabetic foot ulcers are at high risk of infection with multi-drug resistant bacteria, and the assessment of the patient's condition after admission needs to take into account of their BMI, HbA1c, FPG, TG, ulcer course, ulcer size, peripheral neuropathy, peripheral vascular lesions, osteomyelitis, white blood cell count, neutrophil percentage, and use of antimicrobial drugs within the last 3 months. Peripheral blood leukocyte count and neutrophil percentage are not only indicators to evaluate the degree of infection, but also valuable in the early assessment of the risk of infection with drug-resistant bacteria. Further studies are needed to elucidate the mechanism of the effect of low immune cell levels on ulcer infection with multi-drug resistant bacteria.

\author{
Abbreviations \\ MDR: Multidrug-resistant; DFI: Diabetic foot infection; BMI: Body mass index; \\ FPG: Fasting plasma glucose; HbA1c: Glycated hemoglobin; TG: Triglycerides; \\ TC: Total cholesterol; LDL-c: Low-density cholesterol; HDL-c: High-density \\ cholesterol.
}

\section{Acknowledgements}

We thank the physicians from the Department of Endocrinology, the Affiliated Hospital of Jiangnan University for their support.

\begin{abstract}
Authors' contributions
All authors contributed substantially to the work presented in this paper, read and approved the final manuscript. XY designed all the work under the supervision of J-FS. XY designed the research, contributed substantially with data analysis, results interpretations and manuscript editing and approval. XL and LZ collected the patients' data and did indicators analysis. The author(s) read and approved the final manuscript.
\end{abstract}

\section{Funding}

This work was supported by the Hospital Pharmaceutical Research Project of Jiangsu Pharmaceutical Association and Tianqing (No. Q2019096), Wuxi Science and Technology Development Medical and Health Guidance Project (No. CSZ0N1809), Jiangsu Research Hospital Association for Precision Medication (JY202011). The authors declare that they have no fnancial relationship with the organization that sponsored the research, and the funding body was not involved in study design, data collection, analysis and writing of the study.

\section{Availability of data and materials}

The datasets used and/or analysed during the current study available from the corresponding author on reasonable request.

\section{Declarations}

\section{Ethics approval and consent to participate}

This study was carried out in accordance with the recommendations of the Ethics Committee of the Affiliated Hospital of Jiangnan University (Original Area of Wuxi Third People's Hospital) with written informed consent from all subjects.

\section{Consent for publication}

Not applicable.

\section{Competing interests}

The authors declare no competing interests.

\section{Author details}

${ }^{1}$ Department of Pharmacy, Changzhi People's Hospital, Changzhi City, Shanxi Province, China. ${ }^{2}$ Department of Clinical Pharmacy, Affiliated Hospital of Jiangnan University, Wuxi City, Jiangsu Province, China. ${ }^{3}$ Jiangsu Key Laboratory of New Drug Research and Clinical Pharmacy, Xuzhou Medical University, Xuzhou City, Jiangsu Province, China. ${ }^{4}$ Department of National Metabolic Management, Affiliated Hospital of Jiangnan University, Wuxi City, Jiangsu Province, China.

Received: 2 October 2021 Accepted: 9 February 2022

Published online: 21 February 2022

\section{References}

1. BenMoussa M, Khalfallah M, BoutibaBenBoubaker I, Nouira R, Slim A, Jerraya $\mathrm{H}$, et al. Bacteriological and therapeutic profile of diabetic foot infection: a prospective study of 100 patients. La Tunisie Médicale. 2016;94(2):95-101.

2. Tang ZY. The comprehension to the part of diabetic foot infection in Chinese guideline on prevention and management of diabetic foot (2019 edition). World Clini Drugs. 2019;40(9):599-602.

3. Price Bianca L, Lovering Andrew M, Bowling Frank L, Dobson CB. Development of a Novel Collagen Wound Model To Simulate the Activity and Distribution of Antimicrobials in Soft Tissue during Diabetic Foot Infection. Antimicrob Agents Chemother. 2016;60(11):6880-9.

4. Wayne Pa: Clinical and Laboratory Standards Institute: M2-A9[S]. Clinical and Laboratory Standards Institute. Performance standards for antimicrobial disk susceptibility tests 2006

5. Agbi KelechiE, Carvalho Maria, Phan Ha, Tuma Cristiane. Case report: diabetic foot ulcer infection treated with topical compounded medications. Int J Pharm Compd. 2017;21(1):22-7.

6. Belefquih B, Frikh M, Benlahlou Y, Maleh A, Jadid L, Bssaibis F, et al. Diabetic foot infection in Morocco: microbiological profile. Wounds A Compendium of Clin Res and Pract. 2016;28(3):89.

7. Huang X, Deng ZD, Ni YX, Deng M, Hu BJ, Li LY, et al. Chinese experts' consensus on prevention and control of multi-drug resistance organism healthcare-associated infection. Chin J Infect Control. 2015;14(1):741-7.

8. Chinese Diabetes Society. Guidelines for the prevention and control of type 2 diabetes in China (2017 Edition). Chin J Pract Internal Med. 2018;38(04):34-86.

9. China International Exchange and Promotive Association for Medical and Health Care, Diabetic Foot Association. Chinese guideline on diagnosis and treatment of diabetic foot. National Med J of China. 2017;97(4):251-8.

10. $\mathrm{Xu}$ J, Wang PH. Standardized diagnosis and treatment of diabetic foot infection. Chin J Pract Intern Med January. 2016;36(01):3-6.

11. Nicolaas C.Schaper, Jaap J.van Netten, Jan Apelqvist, Sicco A.Bus, Robert J.Hinchliffe, Benjamin A. IWGDF practical guidelines on the prevention and manmagement of diabetic foot disease (2019)[EB/OL]. [2019-06-01]. http://iwgdfguidelines.org/wpcontent/uploads/2019/05/IWGDF Guidelines-2019. pdf

12. Weinstein MP, Lewis JS 2nd. The clinical and laboratory standards institute subcommittee on antimicrobial susceptibility testing: background, organization, functions, and processes. J Clin Microbiol. 2020;58(3):e01864-e1919.

13. Pellizzer G, Strazzabosco M, Presi S, Furlan F, Lora L, Benedetti P, et al. Deep tissue biopsy vs superficial swab culture monitoring in the microbiological assessment of limb-threatening diabetic foot infection. Diabet Med. 2001;18(10):822-7.

14. Mantey I, Hill RL, Foster AV, Wilson S, Wade JJ, Edmonds ME. Infection of foot ulcers with Staphylococcus aureus associated with increased mortality in diabetic patients. Commun Dis Public Health. 2001;3(4):288-90.

15. Fejfarová V, Jirkovská A, Skibová J, Petkov V. Vliv rezistentních patogenů a ostatních rizikových faktorů na cetnost amputací dolních koncetin u pacientů se syndromem diabetické nohy [Pathogen resistance and other risk factors in the frequency of lower limb amputations in patients with the diabetic foot syndrome]. Vnitr Lek. 2002;48(4):302-6.

16. Saltoglu N, Ergonul O, Tulek N, Yemisen M, Kadanali A, Karagoz G, et al. Influence of multidrug resistant organism on the outcome of diabetic foot infection. Int J Infect Dis. 2018;70:10-4. 
17. Chen Y, Ding H, Wu H, Chen HL. The relationship between osteomyelitis complication and drug-resistant infection risk in diabetic foot ulcer: a meta-analysis. Int J Low Extrem Wounds. 2017;16(3):183-90.

18. Katz DE, Friedman ND, Ostrovski E, Ravid D, Amrami N, Avivi D, et al. Diabetic foot infection in hospitalized adults. J Infect Chemother. 2016;22(3):167-73.

19. Cassatella MA. Neutrophil-derived proteins: selling cytokines by the pound. Adv Immunol. 1999;73:369-509.

20. Dubský M, Jirkovská A, Bem R, Fejfarová V, Skibová J, Schaper NC, et al. Risk factors forrecurrence of diabetic foot ulcers:prospective followupanalysis in the Eurodiale subgroup. Int Wound J. 2013;10(5):555-61.

21. Zhang L. Correlation analysis of diabetic foot and BMI, HDL-C and TG in the elderly patients. Chin J Prac Med. 2019;46:7.

22. Bandyk DF. The diabetic foot: Pathophysiology, evaluation, and treatment. Semin Vasc Surg. 2018;31(2-4):43-8.

23. Tecchio Cristina, Cassatella Marco A. Neutrophil-derived cytokines involved in physiological and pathological angiogenesis. Chem Immunol Allergy. 2014;99:123-37.

24. Tecchio C, Micheletti A, Cassatella MA. Neutrophil-derived cytokines: Facts beyond expression. Front Immunol. 2014;5:508.

\section{Publisher's Note}

Springer Nature remains neutral with regard to jurisdictional claims in published maps and institutional affiliations.

- fast, convenient online submission

- thorough peer review by experienced researchers in your field

- rapid publication on acceptance

- support for research data, including large and complex data types

- gold Open Access which fosters wider collaboration and increased citations

- maximum visibility for your research: over 100M website views per year

At BMC, research is always in progress.

Learn more biomedcentral.com/submissions 